\title{
Circuitos punitivos: limitaciones del populismo penal a partir de las prácticas de criminalización de mujeres trans y travestis en una zona roja argentina*
}

DOI: https://doi.org/10.18046/recs.i31.3707

\author{
Punitive Circuits: The Limitations of Penal Populism \\ Regarding Criminalization Practices of Transgender Women \\ and Transvestites in an Argentinian Red-Light District
}

\author{
Aramis Lascano ${ }^{* *}$ \\ Universidad Nacional de La Plata (La Plata, Argentina)
}

Joaquín Vélez ${ }^{* * *}$

Universidad Nacional de La Plata (La Plata, Argentina) Consejo Nacional de Investigaciones Científicas y Técnicas (Argentina)

\footnotetext{
${ }^{*}$ Los resultados del presente trabajo son productos parciales de las investigaciones de posgrado en las que actualmente trabajan sus autores. Las mismas son financiadas por becas de investigación de la Universidad Nacional de La Plata y del Consejo Nacional de Investigaciones Científicas y Técnicas de Argentina. Artículo de investigación recibido el 13.09.2019 y aceptado el 21.02.2020.

** Doctorande en Ciencias Sociales por la Universidad Nacional de La Plata (Argentina). Especialista en Abordaje de las Violencias Interpersonales y de Género y abogade de la misma universidad. Integrante del Área de Estudios de Género del Instituto de Cultura Jurídica, del Núcleo de Estudios en Seguridad de la provincia de Buenos Aires (UNLP) y de la organización RESET-Política de Drogas y Derechos Humanos. Activista y becarie en el Instituto de Cultura Jurídica de la Universidad Nacional de La Plata (Argentina). Correo electrónico: aramislascano@gmail.com ORCID: https://orcid. org/oooo-0002-7900-0833

*** Doctorando en Antropología Social por la Universidad Nacional de San Martín (Argentina). Licenciado en Antropología por la Universidad Nacional de La Plata (Argentina). Becario doctoral del CONICET e integrante del Laboratorio de Estudios en Cultura y Sociedad de la Facultad de Trabajo Social de la Universidad Nacional de La Plata (Argentina). Integrante de la cátedra Perspectivas Antropológicas para la Intervención Social y del Núcleo de Estudios sobre Seguridad en la provincia de Buenos Aires (UNLP). Correo electrónico: jv9891@gmail.com ORCID: https://orcid.org/ooooooo1-9108-5529
} 


\section{Cómo citar/How to cite}

Lascano, Aramis; Vélez, Joaquín (2020). Circuitos punitivos: limitaciones del populismo penal a partir de las prácticas de criminalización de mujeres trans y travestis en una zona roja argentina. Revista CS, 31, 187-215. https://doi.org/10.18046/recs.i31.3707 


\section{Resumen}

A partir de dos investigaciones situadas en la ciudad de La Plata, Argentina, nos focalizamos en el sector urbano denominado zona roja, para comprender la criminalización de mujeres trans y travestis. Para lograr este recorrido, mediante herramientas de indagación urbana e investigación-acción, reponemos ensambles en materia de seguridad entre diferentes agencias estatales y colectivos vecinales para abordar las formas en que dichas prácticas son legitimadas y devienen posibles. La regulación cotidiana sobre los espacios habitados nos permite visualizar disputas por las formas de apropiación, e historizar las formas de control de la oferta de sexo en el espacio público. Bajo dicha casuística, interrogamos limitaciones de la noción de populismo penal. Proponemos la figura de circuitos punitivos para visualizar las especificidades territoriales vinculadas a la inseguridad que tienen las prácticas de control moral y penal sobre la zona roja, y la multiplicidad de personas y agencias que intervienen en su curso.

PALABRAS CLAVE:

zona roja, criminalización, mujeres trans y travestis, populismo penal, circuitos punitivos

This article analyses transgender women and transvestites' criminalization practices in a red-light district, from two investigations located in La Plata city, Argentina. In order to achieve this proposal, we apply urban and action research tools to analyze security ensembles between different state agencies and neighborhood groups, so that the ways in which such practices are legitimized and become possible can be addressed. The daily regulation of inhabited spaces allows us to visualize disputes over the forms of appropriation, and to historicize social control of the supply of sex in the public space. Under this casuistry, we question limitations of the notion of punitive populism. We propose the figure of punitive circuits to visualize the territorial specificities linked to the insecurity that moral and criminal control practices have over the red-light district, and the multiplicity of people and agencies that intervene in its course.

\section{KEYWORDS:}

Red-Light District, Criminalization, Transvestites and Transgender Women, Penal Populism, Punitive Circuits 



\section{Introducción: circuitos punitivos, zona roja, travestis y mujeres trans}

El geógrafo marxista David Harvey (2008) advierte que no es posible pensar en forma separada qué tipo de ciudad queremos y qué tipo de relaciones, estilos de vida, valores estéticos y vínculos con el entorno deseamos. En cambio, los aportes del llamado giro espacial nos permiten problematizar estas complejas relaciones y afectaciones mutuas entre prácticas sociales y formas espaciales, arquitectónicas y urbanas. En dicho sentido, a partir del análisis de la criminalización de mujeres trans y travestis, retomamos la noción de circuito, propia de la antropología urbana, para proponer la de circuito punitivo y posibilitar un análisis situado de las formas de regulación y control, es decir, cómo aquello que ha sido abordado bajo el concepto de populismo penal (Tamayo-Arboleda, 2016) toma su lugar en la vida urbana. Magnani (2014: 3) señala que la categoría circuito contiene la posibilidad de "vincular dominios no necesariamente marcados por la continuidad espacial (...) unir puntos discontinuos y distantes en el tejido urbano. Sin por eso, entretanto, perder la perspectiva de totalidades dotadas de coherencia (...) y de esta forma construir unidades analíticas más consistentes".

En esta dirección, nuestra hipótesis es que, para comprender las formas efectivas de regulación y criminalización en el espacio urbano, es necesario visualizar las complejas relaciones, coyunturas y multiplicidad de agentes que intervienen para modelar la ciudad y sus usos legítimos. Por un lado, pretende indagar en cómo se construyen y expresan estos entramados que dan lugar a la idea de circuito punitivo, para sostener la criminalización de mujeres trans y travestis en una zona roja de Argentina. Y, por otro, pretende reponer las limitaciones de la categoría populismo punitivo, para comprender las dinámicas de violencia y criminalización contemporáneas.

La delimitación y clasificación de lugares, límites y fronteras, tanto producidas como productivas, permiten comprender de forma performativa e interaccional la manera en que se inscriben en la ciudad las disputas y conflictos por sus usos legítimos (Segura; Chaves, 2015). A pesar de su común denominación como zona roja, que guarda cierta afinidad con las nociones urbanas de mancha o pedazo para analizar el entramado de la ciudad (Magnani, 2014), analizar los puntos discontinuos, como en el caso de las instituciones penales, permite comprender otras lógicas de la vida social que no son perceptibles enfocando un grupo o sector específico sin comprender las relaciones recíprocas con esos espacios otros que las hacen posibles (Foucault, 1984). En esta dirección, la noción de circuito también nos proporciona una dimensión temporal donde "es posible identificar y describir un conjunto de puntos localizados espacialmente a lo largo de los cuales determinadas personas, objetos o mensajes se 
mueven durante cierto período de tiempo" (Magnani, 2014:10), siendo contingentes y producto de las interacciones sociales cotidianas, siempre en acto.

Como bien advierte Blas Radi (2018), el uso de categorías paraguas, como personas trans, y la apelación equivalente e intercambiable entre los términos trans, travesti, transexual y transgénero en las narrativas de informes oficiales, organizaciones y académicas, puede operar con cierta lógica de uniformidad para pluralizar biografías, trayectorias y experiencias de colectivos heterogéneos. En este sentido, nos referiremos a la población de mujeres trans y travestis -y solo en otros términos cuando así lo hagan las referencias bibliográficas o usos situados-, reconociendo la inconveniencia de cristalizar una identidad sin comprender su carácter contingente, variable y performativo, así como los esencialismos en los que se puede incurrir al entender que una categoría identitaria es por sí sola explicativa de la identidad de las personas. Por otra parte, retomamos el empleo del término cisgénero-acuñado en la década de 1990 por el científico transexual británico Carl Buijs-, donde el prefijo latín cis, utilizado en geografía y geolocalización para indicar 'de este lado', en oposición a trans (lat. 'del otro lado'), hace referencia a aquellas personas cuya identidad de género coincide con el sexo/género que le fue asignado al nacer y no mantener la norma sexista como término no marcado.

A partir de la convergencia de una investigación que aplica herramientas de la etnografía urbana a temas de inseguridad y otra indagación producto de un marco de investigación-acción como activista en torno a los derechos de mujeres trans y travestis, analizamos algunas tramas urbanas que hacen posible su estigmatización. Mediante el trabajo de campo, que incluyó diversas entrevistas a trabajadoras sexuales, vecines, policías y funcionaries judiciales, así como observación participante en asambleas vecinales, derivas urbanas y relevos de medios locales realizadas entre 2017 y 2019, analizamos los sentidos emergentes del conjunto polifónico y heterogéneo para comprender cómo son posibles las trayectorias criminalizadas y la estigmatización sobre las identidades de mujeres trans y travestis. En este movimiento, delineamos en una primera parte las regulaciones y devenires históricos de la oferta de sexo y su criminalización en Argentina y en la ciudad de La Plata, para luego analizar las formas de articulación en la que participan agencias estatales, vecines ${ }^{1}$ y medios de comunicación para regular el territorio urbano. Finalmente, revisitamos el concepto de populismo punitivo para analizar algunas de sus limitaciones y la posibilidad de imaginar la figura de circuitos punitivos para el análisis situado y la incorporación de una dimensión espacial en las prácticas punitivas y penales.

1. Empleamos la inscripción e en aras de utilizar un lenguaje no sexista y de acuerdo a la temática y propuestas del presente artículo. En ocasiones se mantiene universal masculino (ej. vecinos) para reponer las formas de expresión situadas. 


\section{El control del sexo: regulaciones y reglamentaciones en torno al trabajo sexual en Argentina}

Desde el año 1936, la legislación argentina se adhirió a un modelo abolicionista que sancionaba a todo aquel que lucrara o explotara el ejercicio de la actividad sexual ajena, aunque no prohibiera su ejercicio autónomo. De todas formas, esto no implicaba que no fuese objeto de control judicial o policial informal ni tampoco que estuviera fuera del escrutinio moral (Daich; Varela, 2016; Sabsay, 2011). En la actualidad, coexisten diversas normativas de carácter provincial y municipal que legitiman la persecución y represión de quienes ejercen la prostitución en el espacio público, desplegando facultades de poder de policía, en sentido amplio, para la regulación urbana (Bolla, 1983). A partir de la década del 200o, se produjo una reconfiguración de la administración de la justicia penal local, en concordancia con los lineamientos nacionales e internacionales en materia de trata de personas. Esto tuvo como consecuencia no solo la asignación de competencia especializada en estructuras judiciales para la persecución penal de delitos conexos a la trata de personas en el año 2009 -sobre todo laboral y sexual-, sino que también tuvo un efecto no declarado al cerrar locales y domicilios donde se revelaron situaciones de explotación sexual, tanto en el perímetro urbano de la ciudad (Procuración General de la Suprema Corte de Justicia de la provincia de Buenos Aires, 2013:53-56) como en su periferia.

Como advierten Daich y Varela (2014), los modelos de regulación jurídica concentran su mirada en determinadas formas de la prostitución (callejera, en privados, burdeles, whiskerías, etc.) y, en consecuencia, en ciertas personas -en general, provenientes de los sectores populares-y no así en otras (v. gr., no hay una decisión estatal de perseguir al ejercicio de la prostitución de lujo, destinada principalmente al consumo de sectores de altos ingresos). En este sentido, la clausura de privados en la ciudad de La Plata produjo un desplazamiento de trabajadoras sexuales a las esquinas y calles de la ciudad o directamente a diferentes geografías en búsqueda de otras experiencias (Lascano, 2019).

Hacia fines de la década de 1990, algunas pugnas en torno a la despenalización del trabajo sexual callejero en la Ciudad Autónoma de Buenos Aires y los conflictos que sucedieron a la oferta sexual de travestis y mujeres trans en el paisaje urbano fueron objeto de indagación en el campo de investigación local. Por un lado, Leticia Sabsay (2011) señala cómo la verdadera amenaza que suponía quitar de la punición esta actividad no era tanto su reconocimiento legal, sino más bien la visibilización de otros géneros y sexualidades e intercambios en el espacio social, que desestabilizan creencias heteronormativas como la binariedad genérica, que la sexualidad debe reservarse a la privacidad y que el intercambio sexual debe ser desinteresado 
e idealmente debe darse en relaciones afectivas estables. Por su parte, Martín Boy (2017) prestó especial atención a la construcción de una otredad a la que hay que castigar, alejar y controlar en la delimitación y legitimación de un nosotros, en tanto que los cuerpos e identidades trans y travestis representan una ajenidad por una identidad y expresión de género que desestabiliza ciertos cánones normativos de los vecinos de clases medias-altas del barrio de Palermo, por su clase social -y posiblemente la nacionalidad-y por las prácticas e intercambios que llevan adelante en el espacio público.

Ampliando la mirada hacia la casuística latinoamericana, los trabajos de Botelho de Matos y Campos Ribeiro (2008) sobre Río de Janeiro expusieron cómo la dicotomía entre el día y la noche es una de las características que atraviesa territorios donde se ejerce la prostitución, diferenciando formas de uso y personas que asisten según la hora de la jornada. Este trabajo también expone la necesidad de repensar la categoría del anonimato en las ciudades (Simmel, 1986) como capa protectora frente a las miradas estigmatizadoras en el tema de las personas migrantes, en este caso en función de las identidades trans y travestis (Boy, 2017).

Dichos estudios permiten observar la trama social de la controversia por la oferta de sexo en el espacio público, en la que vecines, trabajadoras sexuales y colectivos organizados, proxenetas, agencias de seguridad, reglamentaciones urbanas, clientes y medios de comunicación intervienen en la disputa por los usos correctos, su regulación diaria y la codificación legal que cristalice la narrativa hegemónica. Estas tensas relaciones permiten observar tanto las fronteras simbólicas y materiales de la ciudad como la manera en que estas son inscriptas en las lógicas situadas de conflicto por cómo (no) se puede utilizar el espacio público y quiénes (no) pueden estar en él.

¿Cuáles son los espacios apropiados para el sexo y la actividad sexual? ¿Qué partes del cuerpo pueden mostrarse públicamente? ¿Qué cuerpos y prácticas pueden estar de forma legítima en la vía pública?

\section{La acumulación de opresiones y desigualdades}

En mayo de 2012, la Cámara de Diputados de la Nación sancionó la Ley de Identidad de Género (Ley 26.743; en adelante, LIG), producto de la tenaz lucha y articulación -y también disputas- del movimiento LGBTTTIQ ${ }^{2}$ y, en particular, del activismo trans y travesti encolumnado en el Frente Nacional por la Identidad de Género, luego de un largo proceso de fortalecimiento de derechos por parte de las personas LGBTTTIQ. La LIG, de vanguardia a nivel mundial, está anclada bajo los principios

2. Este acrónimo, si bien no tiene presunciones exhaustivas, pretende nuclear a lesbianas, gais, bisexuales, travestis, transexuales, transgénero, intersex y queer. 
de autodeterminación, desjudicialización y despatologización de las identidades y corporalidades trans y travestis. Pese a estos avances en conquista de derechos, la inmensa mayoría de las travestis y mujeres trans comparten trayectorias de exclusión social, expulsión o exilio de sus lugares de origen, con una expectativa de vida inferior a los cuarenta años, tienen enormes obstáculos para ejercer sus derechos en el campo de la salud, educación y el trabajo, y sus alternativas laborales se vinculan a mercados informalizados (ATTTA; Fundación Huésped, 2013; Berkins, 2008; Berkins; Fernández, 2005; Instituto Nacional contra la Discriminación, la Xenofobia y el Racismo; Instituto Nacional de Estadística y Censos, 2012; Ministerio Público de la Defensa de la Ciudad Autónoma de Buenos Aires, 2017), en forma similar al resto de los países latinoamericanos. Por otro lado, se han identificado y caracterizado numerosos obstáculos, hostilidades y conflictos recurrentes en las interacciones entre la población de mujeres transexuales y travestis, y las instituciones y agentes de la justicia en la Ciudad Autónoma de Buenos Aires (Radi; Pecheny, 2018).

Sus trayectorias en contextos de encierro suelen venir acompañadas no solo de las violaciones a los derechos humanos que atraviesan a las cárceles en general, sino que también se evidencian problemáticas específicas en función de una matriz penitenciaria y judicial cisexista. Estas incluyen, además de ser asignadas a establecimientos masculinos donde no se considera su identificación como mujeres, travestis o trans; las negativas u obstáculos para el ingreso y uso de cosméticos, el establecimiento de regímenes de visitas solo en función de vínculos biológicos, la discontinuidad en los tratamientos hormonales y la falta de atención adecuada para personas con VIH y enfermedades crónicas, la sobreexposición a las violencias en los traslados, las requisas vejatorias, etc. (Akahatá et al., 2016). Confirman estas tendencias en extremo vejatorias, las muertes, en 2017, de tres mujeres trans y travestis detenidas sin condena firme y por infracción a la Ley de Drogas. Estas tuvieron lugar mientras se encontraban bajo custodia judicial-penitenciaria, luego de ser negada su atención sanitaria y pese al reclamo de la organización Otrans Argentina (2017) y de sus compañeras de pabellón.

Durante la presente década, se ha identificado al colectivo de travestis y mujeres trans como un nuevo blanco predilecto de la guerra contra las drogas, en el creciente uso de un lenguaje bélico para los problemas urbanos en Argentina y la región. La gran mayoría de travestis y mujeres trans en cárceles federales o provinciales se encuentran detenidas por presuntas infracciones a la Ley de Drogas, asociadas a roles fungibles, visibles, inferiores, riesgosos y no violentos en las redes de comercialización (Comisión Provincial por la Memoria, 2018; Otrans Argentina, 2017; Procuración Penitenciaria de la Nación, 2019). Esta realidad es parcialmente compartida con las mujeres cis-como la prevalencia de migrantes latinoamericanas, la 
clase social, etc.- no solo en Argentina (Centro de Estudios Legales y Sociales; Ministerio Público de la Defensa de la Nación; Procuración Penitenciaria de la Nación, 2011), sino también a escala latinoamericana (Pieris; Youngers, 2016) e, inclusive, por fuera de este continente (Consorcio Internacional sobre Políticas de Drogas, 2015; ONU Mujeres, 2014). Dichos datos, interpretados conjuntamente, exhiben la intersección entre géneros, etnia/raza, edad y clase en el impacto diferencial de las políticas de drogas y sobre quienes recaen las consecuencias devastadoras de las políticas prohibicionistas, belicistas y represivas.

\section{La zona roja de La Plata}

La ciudad de La Plata es la capital de la provincia de Buenos Aires, desde que fue planificada, diseñada y fundada en 1882 para ese fin, y cabecera del partido homónimo. Se encuentra ubicada a unos $56 \mathrm{~km}$ en dirección sudeste desde la Ciudad Autónoma de Buenos Aires, formando casi el extremo del corredor sur de la Región Metropolitana de Buenos Aires. Según datos del Instituto Nacional de Estadísticas y Censos, para 2010 contaba con 654324 habitantes. Actualmente, se estima su población en unos 753378 habitantes, y su aglomerado urbano, que incluye los partidos de Berisso y Ensenada, cuenta con unos 899523 habitantes. Es así la cuarta ciudad más poblada del país, y el quinto conglomerado urbano, detrás de Buenos Aires, Rosario, Córdoba y Mendoza.

Hacia comienzos de la década del 20oo, el comercio sexual de la ciudad de La Plata estaba distribuido espacialmente en lugares privados (algunos de los cuales presentaban situaciones de trata de personas con fines de explotación sexual) y en diversos espacios públicos como calles, plazas y esquinas. Dichos espacios contaban con mayor concentración en uno de los límites del casco urbano, que opera con sus avenidas de circunvalación de 100 metros de ancho (ver Figura 1), como frontera simbólica y material del espacio platense (Vélez, 2018).

Por un lado, la oferta callejera de sexo se situaba en lugares cercanos a la Terminal Ferroviaria y la Terminal de Ómnibus, que se encuentran próximas entre sí; y, por otro, en un barrio residencial-comercial y en cercanías al Paseo del Bosque. Esta última área es la que en los últimos años es comúnmente denominada como zona roja y se enmarca en el barrio llamado El Mondongo, del casco urbano de La Plata. Esta zona roja local es atravesada por una de las avenidas diagonales más extensas de la ciudad, que conecta los barrios del este con el centro comercial-administrativo y geográfico respecto del casco urbano fundacional. Esto la convierte, al menos durante el día, en un escenario de circulación permanente de vehículos y transeúntes, 


\section{FIGURA 1 Fotografía satelital de la zona roja de La Plata}

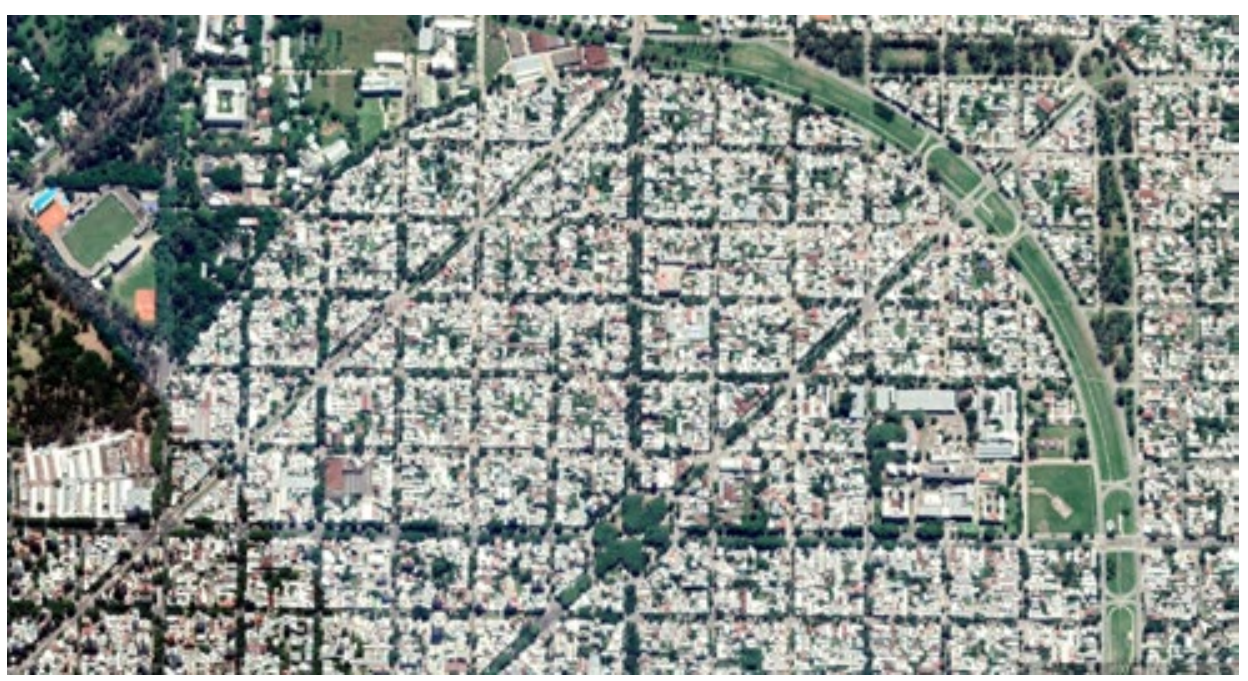

Las líneas rectas de arboledas marcan la presencia de bulevares, su concentración remite a espacios verdes públicos y hacia la derecha es observable la avenida circunvalación en forma de arco.

Fuente: Google Earth.

bienes y servicios, entre grandes árboles, edificios, dependencias estatales (policiales, administrativas, hospitales, escuelas, universidades, etc.), comercios y hoteles de alojamiento. La presencia de travestis y mujeres trans argentinas y migrantes comienza a vislumbrarse en mayor volumen a medida que va llegando la noche. Mientras la mayoría de los comercios van cerrando sus puertas, la oscuridad comienza a prevalecer en el territorio, y diferentes intercambios y sujetes comienzan a circular con mayor regularidad. Clientes sexuales o taxistas, personas que duermen o merodean por la calle-que incluyen niñes y jóvenes-, cirujas $^{3}$, agentes policiales $\mathrm{y}$, sobre todo en los últimos años, personas vinculadas a economías informales o delictivas (como vendedoras/es de drogas ilícitas, proxenetas, etc.).

En la zona roja también hay oferta callejera de sexo de mujeres cis, es decir, de aquellas que se identifican con el género asignado al nacer. Sin embargo, pese a que se ha registrado la participación de algunas de estas personas con la comercialización de drogas y prácticas de criminalización y hostigamiento policial, es notablemente menor. Además, la asociación dominante entre trabajo sexual y narcomenudeo se

3. Ciruja es un término peyorativo que algunas entrevistadas usaron para identificar a sujetos que circulan generalmente durante la noche, suelen consumir drogas, molestarlas, agredirlas, robarles, etc. 
dirige a las travestis y mujeres trans, mientras que les vecines no asocian significativamente a las mujeres cisgénero con la venta de drogas en esta zona roja, y se las suele relacionar, exclusivamente, con el ofrecimiento de sexo comercial.

La convergencia de diferentes políticas de seguridad e intervenciones de vecines del barrio, focalizadas en la zona roja y vinculadas a la prevención situacional del delito, produjo desplazamientos espaciales de la oferta callejera de sexo, similar a intervenciones efectuadas en otras coordenadas geográficas como algunos enclaves de la prostitución en barrios de Londres (Sozzo, 2000). Otros ejemplos más próximos en cuanto a la participación de mujeres trans y travestis en el comercio sexual, los umbrales de violencias de agentes estatales y por parte de terceros hacia ellas, puede encontrarse en lo sucedido en la Ciudad Autónoma de Buenos Aires o en algunas ciudades latinoamericanas, con sus propias especificidades. En algunos centros urbanos de Perú, se explicita la "erradicación de homosexuales, travestis y prostitutas" en los indicadores de los planes de seguridad ciudadana y ha sido definida como una suerte de homotransfobia institucionalizada (Oporto-Patroni, 2018).

\section{De la zona roja a la zona blanca: la asociación entre trabajo sexual y venta de droga}

La sucesión de una serie de procedimientos policiales individuales y masivos, algunos con características de típicas razzias ${ }^{4}$, contribuyeron a que diferentes actores consolidaran el presupuesto general sostenido inicialmente en las investigaciones judiciales llevadas adelante por la policía y la administración de justicia penal, para luego ser replicada por los medios locales de prensa y redes sociales. Este consistía principalmente en los siguientes puntos: que la oferta de sexo es una pantalla, y que las travestis y mujeres trans, en realidad, simulan el ejercicio de la prostitución para participar en el microtráfico de cocaína (Lascano, 2019). En este sentido, se articularon diferentes respuestas, con el objetivo de detener la venta de drogas y la inseguridad en la zona roja, en las cuales el gobierno municipal, provincial y la administración de justicia penal fueron instituciones centrales.

La ciudad de La Plata ha reflejado algunas transformaciones respecto a la criminalización del colectivo de mujeres trans y travestis, con ciertas especificidades que requieren particular atención. Los argumentos legales para la persecución penal en la zona roja han mutado a lo largo del tiempo: desde comienzos de la década

4. Este término es popularmente conocido en Argentina y pretende caracterizar a los operativos violentos de control localizado y sorpresivo que combinan prácticas policiales violentas, detenciones y requisas de un gran número de personas. 
de 1990 hasta fines de la década del 2000, la inmensa mayoría de las detenciones estaban motivadas en presuntas infracciones a faltas y contravenciones asociadas al travestismo (Art. 92, Inc. E, Decr. Ley 8031/73) o a la prostitución callejera (Art. 68, Decr. Ley 8031/73), en apelaciones a figuras como averiguación de identidad de la ley orgánica policial de la provincia de Buenos Aires (Art. 15, Inc. C, Ley 13.482) o simplemente por tareas de prevención policial y presuntos desórdenes urbanos o escándalos en la vía pública (Akahatá et al., 2016).

Durante el año 2013, la oferta de sexo de trans y travestis en el espacio público -y las consecuencias que presuntamente ella suponía- dejó de ocupar el centro de las preocupaciones en los discursos hegemónicos para cederle lugar al reclamo y las denuncias por la participación de mujeres trans y travestis -mayormente, migrantes latinoamericanas- en el delito, particularmente, en la venta de cocaína al menudeo (Lascano, 2019). Comenzaron así a circular asociaciones automáticas de sentido entre las mujeres trans y travestis, migración y narcotráfico, tanto en medios de comunicación locales como entre integrantes del poder ejecutivo local, dirigentes de la Iglesia católica, vecines, funcionaries de la administración de justicia penal, medios de comunicación y otres actores de la sociedad civil que cobraban mayor notoriedad cuando se evidenciaban situaciones de violencia urbana o hechos asociados a la inseguridad.

Las interacciones de las travestis y mujeres trans con las agencias policiales, judiciales y penitenciarias están atravesadas por dinámicas violentas y de violación de los derechos humanos, aunque también deben ser comprendidas tomando distancia de una mirada unilateral que identificaría solo violencia o sometimiento, reconociendo la posibilidad de situaciones de intercambio, resistencia y adecuación, sobre todo con quienes trazan redes de sociabilidad (Daich; Sirimarco, 2014: 31). De todas formas, la violación de su identidad de género en las actuaciones policiales y judiciales, la articulación de fuerzas policiales para la ejecución de razzias en la zona roja, combinando prácticas policiales diversas como requisas corporales y anales por parte de personal policial masculino o desnudez forzosa fueron denunciadas por organizaciones de trans y travestis, y organismos públicos tanto en el sistema judicial local como en el internacional de derechos humanos (Akahatá et al., 2016; Otrans Argentina, 2017).

Sin embargo, no es posible pensar el rol de dichas instituciones por fuera del conjunto social al que pertenecen y excluyendo del análisis las interacciones cotidianas que pueden incidir en mayor o menor medida en las valoraciones, modos de configuración y sentidos en juego (Rodríguez-Alzueta, 2016), a través de la articulación de diferentes demandas, representaciones y narrativas vinculadas al sentimiento de inseguridad (Kessler, 2009). La zona roja, en tanto territorio, no puede ser pensada por fuera de la ciudad o en forma autocentrada: esta constituye el escenario de 
conflictos, intercambios y gestiones entre personas heterogéneas atravesadas por diferentes normas, jerarquías, desigualdades e intereses. Los sentidos compartidos en este suelo securitario (Vélez, 2018) nos lleva a revisitar el enunciado que sugiere Rodríguez Alzueta (2016), esto es, que no hay olfato policial sin olfato social. En esta dirección, nos proponemos comprender la movilización de los repertorios vecinales en torno al espacio urbano de la zona roja, tanto en el plano de los discursos como en el de las prácticas, y prestar atención a cuál es el lugar que ocupan en la gestión de la seguridad local, comprendiendo, en primer término, las condiciones de emergencia y producción de este proceso de organización entre vecinos.

\section{Entre vecinos y vecinazgos}

La categoría de vecino(s) es permanentemente representada en los medios de comunicación locales y también en algunos de los testimonios recabados en ambas investigaciones como una suerte de actor homogéneo y monolítico que establece relaciones de igualdad y vecindad. Aunque su recuento excede los límites de este trabajo, contiene un trasfondo de larga duración en la sociedad argentina (Caimari, 2012; Rodríguez-Alzueta, 2019). Sin embargo, no todas las personas residentes en el barrio son representadas bajo esta categoría: hay travestis y mujeres trans que viven en pensiones y viviendas y otres residentes que no participan de los espacios organizativos e inclusive empatizan con la situación y ciertas reivindicaciones de aquellas. Ramiro Segura (2009:73) señala que "además de un criterio de localización -necesario, pero insuficiente- la categoría nativa vecino remite a ciertas 'dimensiones morales' y de reconocimiento. Así, muchos residentes del barrio no son vecinos y, por ende, parecerían no ser ciudadanos". Esto se vuelve un punto particularmente relevante para observar las relaciones entre las alteridades emergentes del territorio.

En las intervenciones públicas de referentes vecinales en los medios de comunicación locales y en las reuniones con legisladores provinciales y locales, funcionaries judiciales, policiales y del Ejecutivo municipal, es posible observar en forma regular la búsqueda de homogeneización y coherencia de los vecinos y la omisión de conflictos internos como una forma idealizada que se contrapone a otra repudiada (Massey, 2012), producto de acciones ajenas y fuera de control. Si bien no hay homogeneidad al interior de estos grupos, sí existen condiciones unificadoras que construyen moralidades y modos de comprender la realidad a través de cotidianidades y experiencias diversas (Cosacov; Perelman, 2011). 


\section{La Asamblea Vecinal}

En límites de la denominada zona roja fue mapeada la Asamblea Vecinal (AV), formada por motivación de vecines preocupades por hechos delictivos urbanos como robos y entraderas, que asocian a la oferta sexual y de estupefacientes que tiene lugar en el barrio, y que contaba con un antecedente en la conformación de un corredor seguro (Passarelli, 2015). Su inicio oficial, en 2013, se vincula a la muerte en ocasión de robo de un joven médico residente en la zona. Según comentan algunes vecines, este acontecimiento logró convocar cerca de cien personas para deliberar sobre posibles acciones y reclamos como vecinos. Esta asamblea presentaba un perfil parecido al imaginario punitivo: en sus reuniones participaba casi siempre el comisario de la zona, solían pedir más patrulleros, policías y caminantes, podas, luminarias. Manifestaban quejas hacia organismos de derechos humanos y organizaciones sociales, como hacia los funcionaries judiciales que entorpecen las actividades policiales. Existen alarmas vecinales en diferentes zonas del barrio que se han instalado principalmente en los últimos dos años.

Uno de los temas centrales de la asamblea es la existencia de la zona roja. El progresivo aumento de mujeres trans y travestis en esta zona es narrado como causa de la presencia de estupefacientes y la expansión de la inseguridad, identificándolas como quienes "trajeron la droga al barrio", en oposición a las trabajadoras sexuales cis, hacia quienes se relata un pasado romantizado de reciprocidad y cuidado

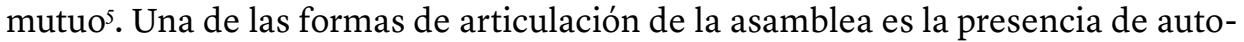
ridades policiales y municipales en la mayoría de las reuniones donde se discuten los problemas y se buscan respuestas que puedan traducirse en acciones sobre el territorio. Pero estas medidas no siempre son negociadas o acordes a las voluntades estatales. Por ejemplo, la iniciativa que la AV encontró para visibilizar sus reclamos por seguridad fue la propuesta de realizar una rebelión fiscal, que implicaba dejar de pagar los impuestos municipales. A mediados de 2018, esta iniciativa tuvo éxito por medio de una red social virtual donde opinaron cientos de vecines (Vélez, 2019). Esto generó tensión en las relativamente amigables relaciones que mantenían con el estamento municipal, aunque las conversaciones y reuniones con dependencias provinciales continuaron fluidas ${ }^{6}$.

5. Una forma de denominar estas transformaciones de la identidad sexual y la asociación con estupefacientes ilegales en términos toponímicos es el empleo de la denominación zona blanca que es registrada en medios de comunicación, redes sociales virtuales y conversaciones en las reuniones vecinales.

6. El actual intendente, Julio Garro, de la gestión de la alianza Cambiemos y representante del PRO, estuvo presente en la inauguración del primer Centro de Monitoreo Barrial que se instaló a comienzos de 2018 en la plaza central del barrio mencionado y donde participó el presidente de la asamblea en representación 
Recientemente, en el curso del año 2019, se tomó la iniciativa de crear un grupo de mensajería instantánea para smartphones sobre seguridad para las situaciones de urgente resolución. El mismo fue publicitado en el grupo cerrado de la red social virtual, donde participan unas 2300 cuentas. La incorporación de herramientas y soportes virtuales se hacía central para poder seguir la controversia y conocer las estrategias de control y vigilancia sobre el espacio habitado. El anuncio versaba: "a partir de este momento el WhatsApp, Seguridad por el Mondongo, está abierto, el que quiera participar puede mandar por privado los siguientes datos: Dirección, nombre apellido y teléfono" (notas de campo, 06.07.2019). Había unos 73 integrantes7. En la descripción del grupo figuraba: "Este grupo solo se creó para temas de seguridad! En nuestro barrio, no para la pavada!" 8 . Desde la comisaría escribieron unos tips sobre qué hacer, previo a mi incorporación en el chat que fue reenviado más tarde por dos personas:

Buenas tardes. Soy el subinspector Gutiérrez Santiago, y soy el jefe de calle de la comisaría y voy a estar pendiente de lo que surja a través de este medio para facilitar y acelerar la llegada de los móviles. Voy a darles algunos consejos para optimizar el funcionamiento y para que este grupo se convierta en una herramienta que ayude en la seguridad de la zona: En primer lugar, llamen al 911. En segundo lugar: procuren esperar al móvil. Tercero y último: por favor eviten realizar comentarios o críticas por este grupo. Soy consciente que seguridad, al igual que los otros pilares del estado tienen fallas, pero este no es el medio para realizar quejas. La idea es no saturar y/o desvirtuar el propósito del grupo. (Notas de campo, 06.07.2019)

Durante los días siguientes, las situaciones denunciadas en el grupo refirieron a la presencia de trabas ${ }^{9}$, compradores de droga, menores sospechosos o que simplemente

de la misma con gran cobertura de los medios locales sobre el acto. Previamente, también había asistido como candidato a algunas de las asambleas vecinales a escuchar sus planteos y se entrevistaron una serie de veces en el palacio municipal durante el transcurso de su gestión.

7. Se emplean nombre ficticios u abreviaciones para preservar el anonimato de vecines, aunque muches interlocutores se mostraron indiferentes respecto al uso del nombre propio. También se emplea en el caso de agentes policiales, aunque se encuentran desempeñando funciones públicas que deberían detentar la publicidad propia de un Estado republicano. El consentimiento informado fue establecido principalmente con moderadores y administradores de grupos virtuales debido a la numerosa cantidad de integrantes, y a la efímera y esporádica participación de algunas personas.

8. Se mantienen los errores ortográficos y de tipeo para retratar la materialidad y las características de inscripción virtual de estos discursos.

9. Forma peyorativa utilizada por vecines y policías para referirse a mujeres travestis y trans. Suele ser antecedido por el artículo masculino los o el negando su identidad femenina o no binaria. 
había muchos travestis en alguna esquina del barrio. En algunos casos describieron las mujeres trans a partir de sus rasgos o vestimentas y en otras compartían imágenes que retrataban jóvenes en supuestas situaciones delictivas. En dichos ejemplos, podemos evidenciar cómo los vínculos entre vecinos legitimados y las autoridades policiales se producen entablando canales de diálogos privilegiados y hacen posible observar lo poroso y liminal entre el olfato policial y el olfato social (Rodríguez-Alzueta, 2016), en torno a la regulación y el uso legítimo del espacio urbano. A continuación, nos detendremos en otro de los dispositivos de articulación como es la realización de reuniones presenciales entre vecinos y autoridades estatales.

\section{De reunión en reunión: pasajes etnográficos sobre la articulación entre vecines y autoridades}

Como señalamos previamente, una de las formas de articulación de la política local y los problemas urbanos es el desarrollo de reuniones (Sarmiento; Tello; Segura, 2007). Esta manera de ir de reunión en reunión (Frederic, 2000) nos posibilita un indicio de cómo rastrear etnográficamente una controversia y seguir a las personas que intervienen en el problema (Venturini, 2010). Una de las dificultades metodológicas en la realización del trabajo de investigación remite a que, a pesar de haber residido ambes autores en los límites del barrio, en gran medida por nuestras posiciones ideológicas, etarias y redes de afinidad, no formábamos parte de dichos círculos sociales. Esto aportó complejidad en el acceso al campo donde en ocasiones nos resultaban no solo ajenos, sino también hostiles y fuertemente interpelantes a nuestros preceptos morales en torno a una perspectiva de derechos e igualdad (Vélez, 2018).

Una tarde de invierno, a mediados de 2019 y en plena campaña electoral municipal, comentaron en redes vecinales que el intendente estaría unas horas más tarde en un club vecinal del barrio, donde en ocasiones tenía lugar la AV. La visita del intendente se concretó con poca presencia de vecines asidues a la asamblea. El presidente de la AV asistió y se conversó principalmente sobre la inseguridad y la zona roja:

Intendente Julio Garro: Hemos hecho una mesa para dialogar con las organizaciones de que emplean a esta gente que trabaja ahí en la zona roja, que no es gente sencilla, la de las organizaciones, está OTrans, varias organizaciones que si bien en algún sentido lamentablemente mezclan mucho la política, acá la política no tiene nada que ver, acá todos somos ciudadanos, yo el miércoles que viene tengo una reunión con Ritondo [ministro de seguridad provincial] para pedirle una nueva planificación de lo que es el tema de la zona roja.

Vecina: Pero no pueden estar en el centro de las familias, yo hace setenta años que vivo en este barrio y fue siempre un barrio familiar, se perdió totalmente, no puede 
ser que nuestros hijos, nuestros nietos, salgan a las 7 y media de la mañana y vean, tengan el espectáculo que tienen, no solo porque están desnudos, sino porque se ve todo lo que hacen.

La zona roja había sido uno de los asuntos controversiales en las promesas de campaña, y les vecines consideraban que el intendente no había cumplido con su promesa. Vemos en su discurso el intento de posicionarse como un vecino más, al mismo tiempo que la vecina presente marcaba sus disensos en torno a la visibilidad de los cuerpos trans y travestis, y la oferta de sexo. No todos los cuerpos tienen lugar en la ciudad y aún menos a plena luz del día. Por otro lado, la negación de la identidad de género -negándolas como sujetas, ya sea refiriéndose como hombres, en masculino, u otras definiciones discriminatorias-y la apelación a los niños-o lo que podrían experimentar elles o la familia- son recursos habituales en las operaciones discursivas de vecinos en esta clase de conflictos (Boy, 2017). La potencialidad de esta apelación reside en que "lxs niñxs figuran en todo discurso político como la imagen de aquellos valores universales que, en la medida en que definirían los valores morales compartidos por todos, estarían más allá de lo político" (Edelman, 2004, como se citó en Sabsay, 2011: 155).

$\mathrm{Al}$ día siguiente tendría lugar una reunión de $\mathrm{AV}$ que, convocada con días de anticipación, había sido difundida por medios de comunicación masivos locales como el periódico El Día, publicado en el grupo de red social virtual y comentado en algunos locales comerciales. La reunión del día anterior con el intendente generó expectativas entre vecines. El lugar propuesto era la biblioteca de uno de los colegios católicos con subvención estatal del barrio, espacio donde se habían realizado reuniones previamente.

El encuentro se extendió unas dos horas con calurosas y polifónicas discusiones:

César Suárez: Buenas tardes, soy César Suárez, titular del comando de patrulla. Lo que me interesa a mí es dar una solución al problema de la inseguridad donde tienen la problemática de estas chicas, como quieran llamarle ustedes, travestis, transexuales y todas esas cosas, yo lo que necesito es que me digan en qué horario podemos encontrar a esta gente y como policías actuar como tal.

Vecino 1: Perdón, ese es su trabajo (...). Tampoco nos tome por tontos señor.

C. S.: Exactamente, no me subestime a mí ni quiero subestimarlo a usted, la pregunta es en qué momento ustedes se sienten más desprotegidos, es lo que yo tengo que venir a revertir. Después hay otra cosa, una gran verdad, porque me pasó a mí en la [comisaría] primera, cuando detuve tres travestis bajó toda la comisión de los derechos humanos que los tenía a cien metros, para ver porqué los habíamos detenido. 
Vecino 2: ¿No los podés llamar que le explicamos?

C. S.: Sí..., quédese tranquilo también nosotros le explicamos.

Vecino 2: No, no, no por la gestión de ustedes simplemente que se dejen de joder con los derechos humanos porque, ¿no?

C. S.: Bueno, pero hay todo un negociado detrás, muchachos, es un negociado, hay que hablar en forma política, la realidad, muchas veces la policía tiene las facultades para hacer lo que tienen que hacer, pero después nos encontramos con estos pequeños escollos, fijensen que los que estamos reunidos acá somos personas grandes, porque la gente joven ya lo asimiló culturalmente que tiene que convivir con esta gente, cosa que yo no estoy de acuerdo.

Vecino 3: Yo pienso que ya no es esa zona roja sexual que veíamos hace cincuenta años, el 90, 95 \% de las de las personas que ejercen la prostitución en nuestro barrio venden droga.

En esta puesta en escena de la política vecinal urbana (Frederic, 200o), es posible observar algunos rasgos de complicidad y reafirmación del carácter estigmatizado hacia la presencia de mujeres trans y travestis. La sola sumatoria de les participantes en dicho convivio nos da algún indicio para pensar las articulaciones entre vecines y agencias estatales: dispuestos en una mesa enfrentada al público, se alineaban las autoridades correspondientes a la Comisaría y Comando de Patrullas, los secretarios municipales -de las áreas de Políticas Públicas en Seguridad y Justicia, de Convivencia y Control Ciudadano, y de Espacio Públicos y Control Ambiental, respectivamente- y el presidente de la Asamblea Vecinal. Frente a elles, cincuenta vecines que superaban los cincuenta años, y trabajadores de prensa del diario con mayor tirada de la ciudad. El escenario: la iluminada biblioteca del colegio católico del barrio con subvención estatal y dependiente del Arzobispado de La Plata.

Los señalamientos de vecines nos remiten a la paradoja que señala Sabsay (2011) en su análisis de las normativas en torno al sexo comercial en la ciudad de Buenos Aires: si por un lado la visibilidad de los cuerpos trans y travestis es denunciada y marcada como violencia visual y una ofensa moral, su levantamiento mediático hipervisibiliza aquello que se quiere ocultar. Si bien consideramos inadecuado atribuir a los medios de comunicación masivos una responsabilidad lineal y sobrejerarquizada en la expansión de la represión o de la extensión del sentimiento de inseguridad, tampoco es apropiado reconocerle un lugar neutro (Focás; Kessler, 2014): hay decisiones editoriales en torno a las voces, representaciones y narrativas que ocupan mayor lugar en la construcción mediática de la realidad social y de la imaginación urbana. La posibilidad de repetición de las noticias en los soportes virtuales crea una 
suerte de eco que es gestionado por vecines, tanto en grupos de mensajería instantánea como en perfiles personales y grupos cerrados de redes sociales virtuales. Otro rasgo de este lugar activo que tiene el público en la construcción mediática se vincula a la producción de la noticia. En ocasiones, las fotografías o videos de cámaras de seguridad privadas en los que se registran acciones y personas estigmatizadas son proporcionados por los vecines del barrio y utilizadas por medios de comunicación para sus narrativas.

\section{Críticas al populismo penal a partir de la criminalización de mujeres trans y travestis: por una noción de circuitos punitivos}

Estos conflictos señalados nos invitan a reflexionar sobre una de las categorías que se han empleado en los recientes lustros para comprender las relaciones de violencia y criminalización hacia determinadas personas y corporalidades estigmatizadas. Nos referimos a la idea de populismo penal o punitivismo desde abajo, que ha permeado el imaginario de iniciativas estatales y análisis intelectuales (Sozzo, 2005). La mayoría de las medidas vinculadas a la prevención situacional y comunitaria del delito se apoyaron en un proceso de creciente intervención municipal iniciada a comienzos de la década de 1990.

Estas reformas se cristalizaron a través de la descentralización, reubicación y redefinición de responsabilidades y funciones de los actores estatales y no estatales en la gestión de la seguridad, facilitadas por el crecimiento de las tasas de victimización y del sentimiento de inseguridad (Kessler, 2009), así como por el encuentro complejo y heterogéneo de dos tendencias. Por un lado, una descripta como descendente o de arriba hacia abajo, en la cual los gobiernos municipales son posicionados frente al desafío de hacer algo para producir seguridad en virtud de desplazamientos impulsados por las estructuras estatales centralizadas; y otra ascendente o de abajo hacia arriba, en la cual los actores políticos locales recuperan demandas para expandir las competencias municipales y reivindican la capacidad de hacerse cargo de la seguridad ciudadana a través de la gestión municipal (Sozzo, 2009). Estas tendencias nos permiten comprender usos de categorías de referencia espacial, como arriba y abajo, para analizar dichas dinámicas en la relación sociedad-Estado.

Al contrastarlo con la casuística relevada, encontramos problemáticas y atolladeros de dicha concepción. Aunque un análisis pormenorizado excede los límites de este trabajo, nos proponemos delinear algunos interrogantes para futuras reflexiones. Máximo Sozzo nos ofrece un rastreo de la categoría acuñada por Anthony Bottoms 
que connota "la punta inicial de un debate acerca de cómo juega una lógica o una estrategia populista en el campo penal contemporáneo" (Sozzo, 2007: 117). Sozzo (2007: 118) señala que uno de los problemas que encontramos en el término "es el que arrastra el concepto del populismo, que es un concepto extraordinariamente debatido en la vida social y política del siglo XX", lo que se traduce en su empleo como "medidas o políticas en el campo penal, que están legitimadas por el hecho de responder a lo que la gente piensa, siente y quiere". En esta dirección, Fernando Tamayo Arboleda (2016: 23) sostiene:

[Existe una] falta de caracterización precisa por parte de los autores que lo han propuesto y su falta de "novedad", así como los problemas prácticos derivados de la aplicación de un concepto teóricamente incompleto y su trasplante a países con realidades distintas a las sociedades occidentales.

Tamayo Arboleda (2016:26) señala como eje problemático la reducción de lo “populista a lo político y lo 'punitivo' al incremento de penas basado en la convicción de la utilidad política de dich a estratagema", lo que evita explicar "por qué la preocupación a nivel político por el delito es populista, ni las razones que llevan a pensar que se puede obtener (...) rédito político". De hecho, en el caso analizado, los discursos electoralistas del actual intendente respecto de la zona roja y mujeres trans y travestis generaron intensos debates y desacuerdos entre discursos celebratorios y condenatorios de las formas despectivas, cisexistas y patologizantes para nombrarlas. En la reunión con vecines de la zona, el intendente de La Plata manifestaba:

Yo estoy convencido que tiene que llevar adelante la erradicación, de hecho, en fecha de campaña en el 2015 fui uno de los que sacó el tema que se me fue un poco la mano en una radio y salieron a castigarme fuertemente. Actualmente me lo recuerdan, eh, yo tengo una postura, muy, muy segura de lo que pienso (notas de campo, 20.06.2019) ${ }^{10}$

Estas líneas no pierden de vista el hecho de que temas controversiales y tabú pueden conseguir impactar en términos mediáticos, a pesar de los desacuerdos y

10. En plena campaña electoral, en 2015, el entonces candidato a intendente de La Plata, Julio Garro, cuando le consultaron si tenía un plan para solucionar los reclamos vecinales alrededor de la zona roja, en una entrevista radial, expresó: "Se prohíbe. Como se prohíbe dar fuego en los kioscos ahora que hay una ley nueva (...). Se prohíbe la prostitución en la calle, como se prohíbe un cabaret (...). A lo mejor, darles una mano desde lo psicológico, desde lo médico. No se me ocurre darle trabajo a un travesti cuando digamos hay madres y padres en nuestra ciudad con hijos que tienen hambre. Es una locura. Yo he pasado por ahí muchas veces, con mis hijas, y están los travestis en bolas (...). Aparte no es eso solo, es todo lo que eso conlleva: las drogas, la venta de drogas" (Misdos centavos, 2015). 
disensos. Actualmente, muchas formas políticamente incorrectas son reproducidas por la prensa tanto en su defensa como en su acusación, operando como estrategias de visibilidad, tal como se ha evidenciado en las recientes campañas electorales de tendencias punitivistas en América. Pero una vez más se pone el acento en la heterogeneidad y complejidad que atraviesa aquello que quiere reducirse y estabilizarse en la idea de pueblo o popular.

Precisamente, si retomamos el planteo de Elías y Scotson (2016), podemos encontrar cómo se producen escisiones y distinciones culturales a partir de preceptos morales entre personas que comparten muchos rasgos estructurales y posicionales pero que, sin embargo, se perciben bajo la división ellos/nosotros. Podemos preguntarnos, en estos casos, de qué lado queda lo popular una vez que dejamos los esencialimsmos sustantivistas y evidenciamos sus rasgos contingentes, performáticos e incompletos, parafraseando a Ernesto Laclau (2005). Por otro lado, homogeneizar lo popular bajo la forma punitivista no nos permite imaginar las formas de resistencia, de oposición y de negación del estigma y la criminalización. Las organizaciones que nuclean mujeres trans y travestis, les activistas de derechos humanos y antirrepresivos tienden sus lazos territoriales y permiten articular estrategias que, aunque artesanales y subalternas, crean cierto cortocircuito dentro de lo que proponemos caracterizar como circuitos punitivos.

La realización de movilizaciones y marchas donde confluyen sindicatos, movimientos sociales, estudiantiles y organizaciones políticas en reclamo del hostigamiento policial, la represión de la protesta, los femicidios y travesticidios o la impugnación pública al proyecto de Código de Convivencia propuesto en 2018 por la gestión municipal de la alianza Cambiemos, que gobierna la ciudad desde 2015, son algunas expresiones de qué es lo que puede estar contenido como potencia bajo el signo de lo popular. El mural que se observa en la Figura 2 es una de las formas en que se inscribe su resistencia en el espacio público barrial.

El significante significante "popular" también ha sido reivindicado por los movimientos feministas de América Latina -o Abya Yala según la denominación kunapara oponerse a las posturas y directivas eurocéntricas, visibilizando las formas propias de resistencia y de lucha que no siempre siguen los senderos estipulados por sus pares occidentales (Korol, 2016). De la misma forma, el colectivo de mujeres trans y travestis no es ajeno a estas tensiones y complejidades. Muchas personas provenientes de sectores populares y migrantes encuentran formas de organización en estos espacios heterogéneos que se articulan desde el campo popular en contra de las formas de dominación cisheteropatriarcal y capitalista. 


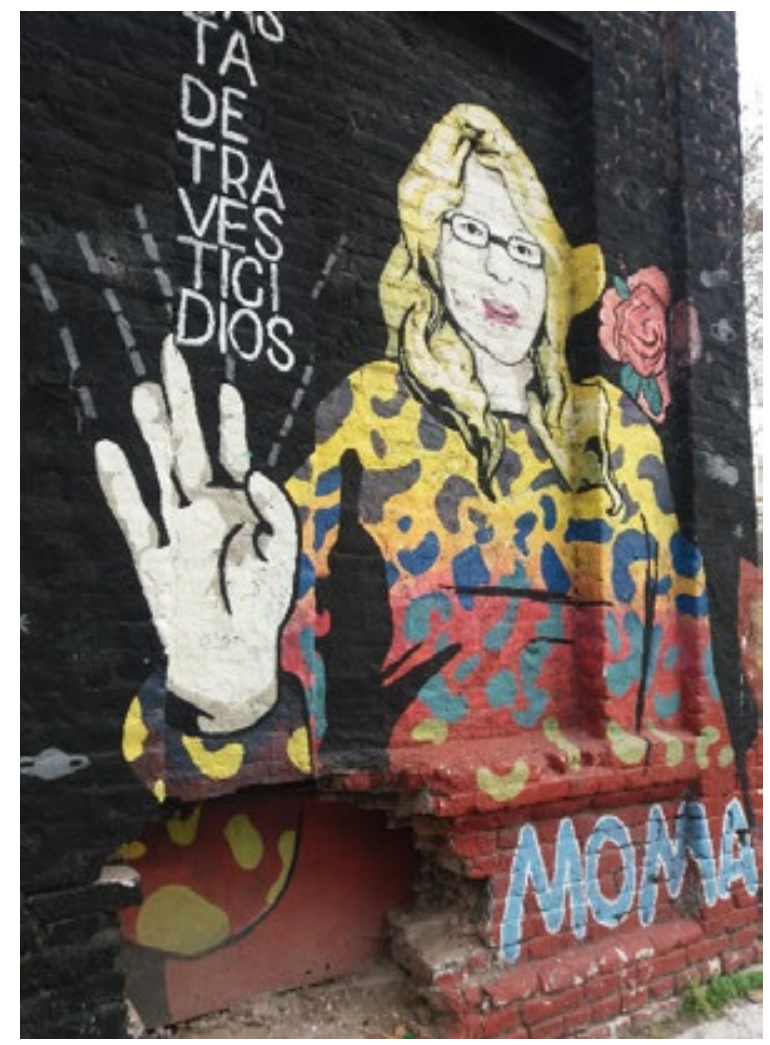

Fuente: elaboración propia.

\section{Circuitos y cortocircuitos en los suelos securitarios}

Esta articulación entre múltiples agencias y personas descritas se hace abordable a partir del análisis de las interacciones que son englobadas bajo la noción de circuito punitivo. Dichas conexiones son cambiantes y dinámicas, lo que hace necesario considerar las heterogeneidades existentes en cada nivel y articulación, cuestión que el concepto de populismo aplana en demasía. Las disputas y tensiones que se introducen por las organizaciones de derechos humanos y activistas en contra de las prácticas de criminalización, aunque escasamente analizadas aquí, permiten imaginar la posibilidad de hacer cortocircuitos, elaborando estrategias que permitan encontrar las hendijas a las tendencias punitivistas existentes en los diferentes 
sectores analizados. En la Figura 3 es posible observar otro sector del mural que mencionamos previamente como inscripción visual de la protesta.

A la vez que encontramos mecanismos de dominación ejercidos en los términos establecidos desde abajo (Sozzo, 2007), pueden también circular por abajo en un sentido lateral, de contigüidad, de vecindad. Gilles Deleuze (1999) postulaba que, en las sociedades de control, los puntos de vigilancia ya no corresponden a un observador central, como en el modelo disciplinar del panóptico, sino que esos puntos se diseminan por el espacio. Ya no se trata de controlar lugares cerrados, sino espacios abiertos. La figura del círculo, que es asociada en ocasiones a mecanismos políticos de horizontalidad y equidad -a diferencia del esquema piramidal jerárquico-, es también la forma en la que todos los puntos pueden observarse entre sí. De

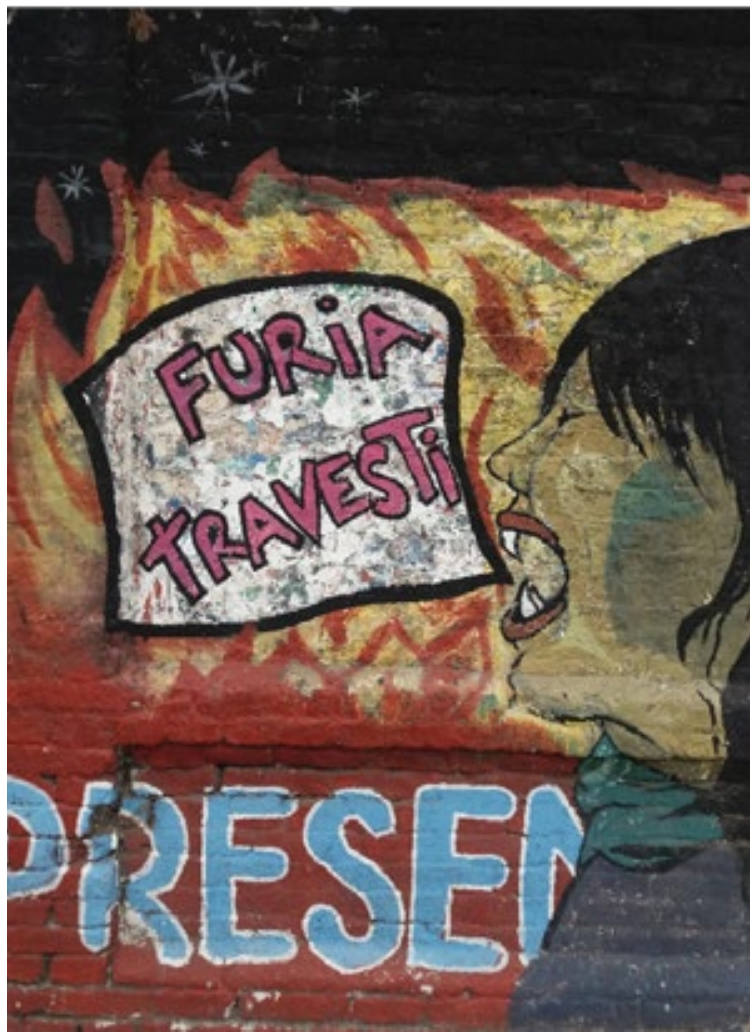

Fuente: elaboración propia. 
alguna forma, los controles morales entre los habitantes del territorio relevado y su soporte en mecanismos tecnológicos, como mensajería instantánea, redes sociales virtuales y la proliferación de cámaras públicas y privadas, nos permiten imaginar cierta analogía con el esquema circular del control.

En todo caso, los circuitos punitivos pueden establecer esas conexiones entre elementos estatales, vecinales y privados, pero siempre puestas en movimiento, enfocando sus formas relacionales y de afectación recíproca en la gestión diferencial de los ilegalismos (Foucault, 2015). A diferencia de otros conceptos como disciplina, dispositivos o ensambles, circuito implica otorgar la dimensión del movimiento, conectando puntos discontinuos en el espacio, pero que son puestos en relación por las propias dinámicas sociales (Magnani, 2014). Se trata de matizar constructos totalizantes como sociedad disciplinaria o sociedad de control, espacios abiertos o cerrados, para encontrar cómo diversos regímenes y estrategias son puestas en acción, no tanto de manera contradictoria como complementaria, para generar pliegues, zonas de contacto y convergencia.

\section{Reflexiones finales}

Las prácticas de criminalización de las trabajadoras trans y travestis de la zona roja de La Plata son posibles gracias a la múltiple articulación de controles informales vecinales, las agencias públicas judiciales y de seguridad municipales y provinciales, y medios de comunicación locales que refuerzan y difunden los sentidos estigmatizantes socialmente disponibles. La noción de circuito punitivo nos permitió incorporar una dimensión espacial y temporal que da cuenta de la repetición y similitud de las trayectorias de trabajadoras sexuales trans y travestis, destinatarias de múltiples opresiones y acumulación de desventajas en sus trayectorias vitales.

Bajo la figura de circuito punitivo, también fue posible dimensionar algunas de las resistencias que producen cortocircuitos en las tendencias punitivas y en contra de la criminalización. De la misma manera, podemos afirmar que, si las prácticas de represión y regulación informal estatales no son posibles sin estos ensambles y formas de legitimación ciudadanas, su reverso, es decir, las formas de resistencia y activismos por los derechos humanos, se producen de manera similar, articulando las legislaciones vigentes e instancias institucionalizadas junto a formas organizativas ciudadanas con presencia en los territorios donde se evidencia mayor vulneración y violencia. Aunque artesanales y en marcada desigualdad, nos abren algunos caminos posibles para pensar y practicar la construcción de las ciudades y comunidades que deseamos habitar. 


\section{Referencias}

Akahatá; Agrupacion Nacional Putos Peronistas; Cooperativa de Trabajo La Paquito; Abogados y abogadas del NOA en Derechos Humanos y Estudios Sociales; Arte Trans; Asociación de Lucha por la Identidad Travesti y Transexual...; Personas Trans Autoconvocadas de Argentina (2016). Informe. Situación de los derechos humanos de las travestis y trans en la Argentina. Recuperado de https://bit.ly/2wyPDKo

ATTTA; Fundación Huésped (2013). Ley de Identidad de Género y acceso al cuidado de la salud de las personas trans en Argentina. Buenos Aires: Fundación Huésped.

Berkins, Lohana (2008). Cumbia, copeteo y lágrimas. Informe nacional sobre la situación de travestis, transexuales y transgéneros. Buenos Aires: ALITT.

Berkins, Lohana; Fernández, Josefina (2005). La gesta del nombre propio. Informe sobre la situación de la comunidad travesti en la Argentina. Buenos Aires: Ediciones de las Madres de Plaza de Mayo.

Bolla, Mario (1983). Algunas reflexiones en torno al Poder de Policía Municipal. Series monográficas. La Plata: Ediciones del Instituto de Derecho Municipal y Urbanismo.

Botelho de Matos, Rogério; Campos Ribeiro, Miguel Angelo (2008). Territórios da Prostituição nos Espaços Públicos da Área Central do Rio de Janeiro. Boletim Goiano De Geografia, 15(1), 59-78. Recuperado de https://bit.ly/2GE5mwm

Boy, Martín (2017). Cuerpos e identidades extranjerizados: vecinos/as y travestis en disputa. El caso de la zona roja de Palermo, 1996-2005. En Fronteras en la ciudad: (Re)producción de desigualdades y conflictos (pp. 45-63), compilado por Martín Boy; Mariano Perelman. Buenos Aires: Teseo.

Caimari, Lila (2012). Mientras la ciudad duerme. Pistoleros, policíasy periodistas en Buenos Aires, 1920-1945. Buenos Aires: Siglo XXI.

Centro de Estudios Legales y Sociales; Ministerio Público de la Defensa de la Nación; Procuración Penitenciaria de la Nación (2011). Mujeres en prisión: los alcances del castigo. Buenos Aires: Siglo XXI.

Comisión Provincial por la Memoria (2018). El sistema de la crueldad XII: sobre lugares de encierro, políticas de seguridad y niñez en la provincia de Buenos Aires. La Plata: Comisión Provincial por la Memoria.

Consorcio Internacional sobre Políticas de Drogas (2015). Documento informativo del IDPC. Políticas de drogas y mujeres: abordando las consecuencias del control perjudicial de drogas. Recuperado de https://bit.ly/2ItAoe3 
Cosacov, Natalia; Perelman, Mariano (2011). Modos de apropiación de la ciudad, conflicto y gestión del espacio urbano. La construcción de fronteras en la ciudad de Buenos Aires. En La cuestión urbana interrogada: transformaciones urbanas, ambientales y políticas públicas en Argentina (pp. 291-322), compilado por Mercedes Di Virgilio; Hilda Herzer; Gabriela Merlinsky; María Carla Rodríguez. Buenos Aires: Café de las Ciudades.

Daich, Déborah; Sirimarco, Mariana (2014). Policías y prostitutas: el control territorial en clave de género. PUBLICAR, 12(17), 27-45.

Daich, Déborah; Varela, Cecilia (2016). Entre el combate a la trata y la criminalización del trabajo sexual: las formas de gobierno de la prostitución. Delito y Sociedad, 2(38), 63-87.

Deleuze, Gilles (1999). Posdata sobre las sociedades de control. En El lenguaje libertario (pp. 105-110), compilado por Christian Ferrer. Buenos Aires: Grupo Editor Altamira.

Elías, Norbert; Scotson, John (2016). Establecidos y marginados. Una investigación sociológica sobre problemas comunitarios. Buenos Aires: FCE.

Frederic, Sabina (2000). De reunión en reunión. La observación participante en el conocimiento etnográfico de los procesos políticos “urbanos”. Horizontes Antropológicos, 6(13), 195-216.

Focás, Brenda; Kessler, Gabriel (2014). ¿Responsables del temor? Medios y sentimiento de inseguridad en América Latina. Nueva Sociedad, 249, 137-148.

Foucault, Michel (1984). Des espaces autres. Architecture, Mouvement, Continuité, 5, 46-49.

Foucault, Michel (2015). Vigilar y Castigar. Nacimiento de la prisión. Buenos Aires: Siglo XXI.

Harvey, David (2008). El derecho a la ciudad. New Left Review, 53, 23-39. Recuperado de https:// bit.ly/2lOCVop

Instituto Nacional contra la Discriminación, la Xenofobia y el Racismo; Instituto Nacional de Estadística y Censos (2012). Primera Encuesta sobre Población Trans 2012: Travestis, Transexuales, Transgéneros y Hombres Trans. Buenos Aires: Ministerio de Justicia y Derechos Humanos de la Nación.

Kessler, Gabriel (2009). El sentimiento de inseguridad: sociología del temor al delito. Buenos Aires: Siglo XXI.

Korol, Claudia (2016). Feminismos populares. Las brujas necesarias en tiempos de cólera. Nueva Sociedad, 265, 142-152.

Laclau, Ernesto (2005). La razón populista. Buenos Aires: FCE.

Lascano, Aramis (2019). La persecución penal a travestis y mujeres trans en la "zona roja" de la ciudad de La Plata [Trabajo final integrador]. Universidad Nacional de La Plata, La Plata, Argentina. 
Magnani, José (2014). Circuito: propuesta de delimitación de la categoría. Ponto Urbe, 15, 1-14.

Massey, David (2012). Un sentido global de lugar. Barcelona: Icaria.

Ministerio Público de la Defensa de la Ciudad Autónoma de Buenos Aires (2017). La revolución de las mariposas: a diez años de la gesta del nombre propio. Buenos Aires: Ministerio Público de la Defensa de la Ciudad Autónoma de Buenos Aires.

Misdos centavos (23 de mayo de 2015). Julio Garro, candidato del PRO en La Plata, sobre los travestis [Archivo de video]. Recuperado de https://bit.ly/2HUCZft

ONU Mujeres (2014). A Gender Perspective on the Impact of Drug Use, the Drug Trade and Drug Control Regimes. Informe de políticas. Recuperado de https://bit.ly/2J3w6tw

Oporto-Patroni, Gabriela Jesús (2018). La “erradicación” de homosexuales y personas trans: análisis de los planes de seguridad ciudadana de Lima Metropolitana y sus distritos. En Informe temático sobre Derechos Humanos de personas trans, lesbianas, gays y bisexuales en el Perú. Derecho a la igualdad de las personas LGBT en el Perú: perspectivas jurídicas y políticas (pp. 154-166), coordinado por Promsex. Lima: Promsex.

Otrans Argentina (2017). Situación sobre el colectivo transy travesti privadas de la libertad. Informe presentado al Relator Especial de las Naciones Unidas, sobre la Tortura y otros tratos o penas crueles, inhumanos o degradantes. Recuperado de https://tbinternet.ohchr.org/Treaties/ CEDAW/Shared\%2oDocuments/ARG/INT_CEDAW_NGO_ARG_25486_S.pdfPassarelli, Ana Milena (2015). Corredor seguro: uso, disputasy apropiación del espacio público en la ciudad de La Plata (Tesis de grado). Universidad Nacional de La Plata, Facultad de Humanidades y Ciencias de la Educación, La Plata.

Pieris, Nischa; Youngers, Coletta (2016). Mujeres, políticas de drogasyencarcelamiento: guía para la reforma de políticas en América Latina y el Caribe. Recuperado de https://bit.ly/2TxDfmW

Procuración General de la Suprema Corte de Justicia de la provincia de Buenos Aires (2013). Memoria en materia de delitos conexos a la trata de personas. Período 2009-2013. Recuperado de https://bit.ly/2lF2c4m

Procuración Penitenciaria de la Nación (2019). Informe anual 2018: la situación de los derechos humanos en las cárceles federales argentinas. Buenos Aires: Procuración Penitenciaria de la Nación.

Radi, Blas (2018). De significados e insignificantes. Revista Institucional de la Defensa Pública de la Ciudad Autónoma de Buenos Aires, 8(14), 288-293.

Radi, Blas; Pecheny, Mario (2018). Travestis, mujeres transexuales y tribunales: hacer justicia en la Ciudad Autónoma de Buenos Aires. Buenos Aires: Jusbaires.

Rodríguez-Alzueta, Esteban (2016). La máquina de la inseguridad. Buenos Aires: EME. 
Rodríguez-Alzueta, Esteban (2019). Vecinocracia: olfato socialy linchamientos. La Plata: Estructura Mental a las Estrellas.

Sabsay, Leticia (2011). Fronteras sexuales. Espacio urbano, cuerpos y ciudadanía. Buenos Aires: Paidós.

Sarmiento, Julio; Tello, Claudia; Segura, Ramiro (2007). Ciudadanía, sociedad civil y participación en políticas públicas: la experiencia de los foros vecinales de seguridad en el municipio de La Plata. Katálysis, 10(2), 187-196.

Segura, Ramiro (2009). Paisajes del miedo en la ciudad. Miedo y ciudadanía en el espacio urbano de la ciudad de La Plata. Cuaderno Urbano, 8(8), 59-91.

Segura, Ramiro; Chaves, Mariana (2015). Introducción. Una antropología de prácticas juveniles en la ciudad. En Hacerse un lugar: circuitos y trayectorias juveniles en ámbitos urbanos (pp. 11-22), editado por Mariana Chaves; Ramiro Segura. Buenos Aires: Biblos.

Simmel, Georg (1986). Sociología: estudios sobre las formas de socialización. Madrid: Alianza.

Sozzo, Máximo (200o). ¿Hacia la superación de la táctica de la sospecha?: notas sobre prevención del delito e institución policial. En Detenciones, facultades y prácticas policiales en la ciudad de buenos aires (pp.3-41), editado por Centro de Estudios Legales y Sociales; Centro de Estudios para el Desarrollo de Chile. Buenos Aires: CELS.

Sozzo, Máximo (2005). Metamorfosis de los discursos y prácticas sobre la seguridad urbana en la Argentina. En Reformas policiales en las Américas. Experiencias y desafios (pp. 39-57), editado por Lucía Lammert; John Bailey. México: Siglo XXI.

Sozzo, Máximo (2007). ¿Metamorfosis de la prisión? Proyecto normalizador, populismo punitivo y “prisión-depósito” en Argentina. URVIO, 1, 88-116.

Sozzo, Máximo (2009). Gobierno local y prevención del delito en la Argentina. URVIO, 6, 58-73.

Tamayo-Arboleda, Fernando León (2016). La limitada capacidad del concepto de populismo punitivo como herramienta de interpretación del sistema penal colombiano. Revista Criminalidad, $58(3), 21-35$.

Vélez, Joaquín (2018). Suelos securitarios. Hacia una antropología urbana de las asociaciones vecinales por la seguridad en la ciudad de La Plata, Argentina. Territorios, 39, 47-70.

Vélez, Joaquín (2019). Ciudades, tecnologías e (in)seguridades: la imbricación de redes sociales y servicios de mensajería en la (auto)gestión securitaria del espacio urbano. Etnografías Contemporáneas, 5(9), 182-203.

Venturini, Tomasso (2010). Diving in Magma: How to Explore Controversies with Actor-Network Theory. Public Understanding of Science, 19(3), 258-273. 